\title{
TEORIA E PRÁTICA NA CONSTRUÇÃO DO CONHECIMENTO EM ADMINISTRAÇÃO
}

\author{
1- Abdulah Bubacar Djaló* \\ Doutorando em Administração pelo Pontifícia Universidade Católica do Paraná - PUC-PR, Curitiba/PR, Brasil. \\ Professor da Universidade Amílcar Cabral - UAC, Bissau, Guiné Bissau. \\ abdjalo@gmail.com \\ http://lattes.cnpq.br/2534378867997327
}

\section{2- Mário Procopiuck}

Doutorando em Administração pelo Pontifícia Universidade Católica do Paraná - PUC-PR, Curitiba/PR, Brasil. mario.p@pucpr.br

http://lattes.cnpq.br/2464341539930740 


\section{TEORIA E PRÁTICA NA CONSTRUÇÃO DO CONHECIMENTO EM ADMINISTRAÇÃO}

\section{RESUMO}

O objetivo principal deste ensaio é centrado na tese de que a divisão dos estudos organizacionais em teoria organizacional e em prática organizacional não está contribuindo para o desenvolvendo de conhecimentos na área das ciências da administração. Para tal, iniciamos abordando as formas subjetivista e objetivista de conhecimento e sobre três modelos de conhecimento teórico, com o intuito de evidenciar como esta divisão tem desencorajado o desenvolvimento de conhecimentos mais adequados à teoria das organizações. Posição essa, em seguida, sustentada mediante da discussão sobre as visões fenomenológicas e pós-estruturalistas de construção do conhecimento. Concluímos o ensaio com breves consideraç̃̃es sobre o processo organizacional, levantando sugestões sobre possibilidades de ampliação e melhor aproveitamento do conhecimento se relegada a segundo plano a divisão putativa entre teoria e prática na área de estudos organizacionais

\section{Palavras-Chave}

Teoria organizacional; comportamento organizacional; conhecimento cientifico; estruturalismo; subjetivismo e objetivismo.

\section{THEORY AND PRACTICE IN THE CONSTRUCTION OF THE KNOWLEDGE IN ADMINISTRATION}

\section{ABSTRACT}

The main purpose of this study is to try to sustain the thesis that the division of organizational studies into organizational theory and organizational behaviour is obstructing the further development of knowledge in administration. To argue that point we begin our paper carrying out a brief consideration on subjectivist and objectivist forms of knowledge and on the three models of theoretical knowledge in order to demonstrate how this division has discouraged the development of knowledge best suited to theories of organization. This position is further supported through a brief presentation of relevant phenomenological and post-structural insights. The paper concludes with a brief sketch of the organizational process and suggests how our knowledge might be furthered by abandoning the putative distinction between theory and practice in the domain of organization studies.

\section{Keywords}

Organization theory; organizational behaviour; scientific knowledge; structuralism; subjectivism and objectivism. 


\section{Introdução}

Uma diversidade de opiniões já foi emitida a respeito das limitações quanto às influências que as ciências administrativas podem exercer sobre o mundo real. Para alguns, o baixo impacto estaria no distanciamento real e metodológico entre o sujeito e o objeto de estudo. As pesquisas organizacionais teriam, pois, se tornado excessivamente abstratas (AUDET, 1986). Nessa linha, por exemplo, estão as tentativas de conceituar organizações como série de conversações que contribuiriam para constituir as próprias organizações a partir de derivações de termos relacionados a paradigmas, métodos e suposições resultantes de conversações prévias (CLEGG; HARDY, 1999, p. 30). O distanciamento em relação ao contexto de atuação de praticantes, que lutam por resultados imediatos, tende, se ocorrer, a levar comunidade acadêmica a produzir discursos herméticos e auto-referidos (MATTOS, 2003, p. 49). A redução da lacuna entre a teoria e os seus efeitos práticos exigiria, portanto, dos estudiosos em organizações, ao invés de voltarem-se exclusivamente para abstrações e formulações puramente teóricas, maior concentração de esforços em questões com efetivo potencial para auxiliar os praticantes na realização de suas atividades diárias.

Há também argumentos que defendem que o obstáculo para maior aderência entre teoria e prática residiria na falta de rigor positivista na condução das pesquisas em administração. Sob este ponto de vista, a fissão entre as ciências administrativas e a práticas gerenciais seria reflexo da ausência de preocupação do desenvolvimento teórico com sua validação empírica. Entretanto, como afirmam Marsden e Townley (1999, p. 41) e Reed (1999, p. 83-84), a abordagem positivista, que busca a construção de teorias com raízes no mundo empírico, mesmo para os praticantes, não tem garantido sucessos permanentes e com grandes impactos em termos de resultados práticos para as organizações.

Finalmente, há quem defenda que a solução seria pura e simplesmente ignorar a existência do problema. A partir desta perspectiva, as ciências administrativas e as práticas gerenciais deveriam ser vistas apenas como dois jogos distintos de palavras; logo, não deveria ser esperada reciprocidade em termos de contribuição entre ambas. Nestas condições, como defendem Astley e Zammuto (1992), não existiriam problemas relevantes a serem enfrentados para esclarecer as relações entre teoria e prática em estudos organizacionais. Pelo contrário, a tentativa de contribuição dos cientistas organizacionais para a prática gerencial mediante desenvolvimento de complexas abordagens para captação, sistematização, interpretação e expressão de realidades acabaria, pois, por dificultar a compreensão e aplicação por praticantes.

A suposta disjunção entre teoria e prática residiria nos fundamentos epistemológicos sob os quais os acadêmicos não-praticantes conduzem as suas atividades de construção do conhecimento (BOURDIEU, 1990). Logo, o desenvolvimento de conhecimentos com consistência teórica e utilidade prática teria de passar pela busca de coerência ontológica e epistemológica de seus fundamentos. Abrindo, com isso, caminho para que análises mais sólidas, tanto por parte de práticos quanto de teóricos, fossem, ao longo do tempo, se firmando dinamicamente no campo. Assim, considerando a emergência do conhecimento a partir da conjunção dinâmica entre teoria e prática, “... se fecha o ciclo que permite que a teoria e a prática se animem uma à outra" (OSTSMAN, 1978, p. 34). Evitando-se, com isto, que haja, como apontam Marsden e Townley (1999), um "divórcio entre teoria e prática organizacional" (p. 32), a exemplo da segregação destas duas dimensões do conhecimento organizacional institucionalizada em publicações como a Academy of Management Journal (prática) e Academy of Management Review (teoria).

Diante dessas diferentes perspectivas, ao invés de deixar de enfrentar a questão ou, dicotomicamente, tentar estabelecer um elo entre a teoria e a prática, defendemos uma abordagem que procura demonstrar que a debilidade da vinculação entre essas duas dimensões ainda não estaria merecendo a atenção necessária. O que, conseqüentemente, poderia aguçar o desenvolvimento de um processo de clivagem entre teóricos e práticos, com reflexos prejudiciais para a própria evolução dos estudos organizacionais. Logo, o abandono da problematização da relação entre teoria e prática para compreensão das organizações não se sobressai como solução razoável, haja vista que, de acordo com Marsden e Townley (1999), isto não mudaria o fato de permanecer existindo e ser amplamente utilizada a teorização a respeito de causas e efeitos como meios de buscar referenciais para agir, tanto em meios acadêmicos quanto de praticantes. Assim o é porque “a maioria das práticas operacionaliza alguma teoria, por mais implícita, vaga e contraditória que ela possa ser. De fato, 'prática' é um constructo teórico e a teorização é, em si mesma, uma prática" (p. 32).

Com a abordagem proposta, por permitir que se considere, com profundidade e de modo encadeado, as 
complexas relações entre teoria e prática e, a partir disso, que se incorpore nas análises condições que tornem possível a construção de conhecimentos mais robustos, há tendência de que aquilo que a priori poderia ser visto como dicotômico deixe de sê-lo. Enfatizamos que o problema realmente existe e transcende à questão de simplesmente tratar da disjunção entre a teoria e a prática com foco mais voltado em defesa de uma ou de outra. O problema, neste caso, tem dimensão mais ampla por abranger também o distanciamento das relações as entre as teorias organizacionais, principalmente assentadas em abordagens estruturais, e o comportamento organizacional em si.

O objetivo deste estudo, portanto, é tentar mostrar como as ênfases epistemológicas que resultam na divisão do campo de estudos em Administração em, de um lado, ciências das organizações e, de outro, práticas gerenciais, constituem-se em severa obstrução para o desenvolvimento de conhecimentos científicos com maior potencial para apreender, sistematizar, interpretar e expressar a realidade, independentemente de perspectivas meramente práticas ou teóricas.

\section{Conhecimentos Subjetivistas e Objetivistas em Estudos Organizacionais}

De início, partindo de uma perspectiva analítica ampla para compreensão da produção de conhecimentos, é importante destacar que os pressupostos ontológicos são antecedentes lógicos das opções epistemológicas e dos métodos explicativos, e normalmente identificados como fontes de profundas divergências paradigmáticas nas ciências sociais (KING; KEOHANE; VERBA, 1996). As escolhas ontológicas dizem respeito aos tipos consistentes de entidades sociais cujas existências os analistas podem razoavelmente assumir (TILLY; GOODIN, 2006, p. 10). Com base em supostos ontológicos sobre qual seria a natureza da realidade, os defensores dos paradigmas positivista e pós-positivista responderiam que a realidade é objetiva, ao passo que os alinhados ao paradigma construtivista retorquiriam no sentido de que a realidade é subjetiva e múltipla (SAUTU et al., 2005, p. 40). Assim, partindo de uma perspectiva ontológica, serão tratados o subjetivismo e o objetivismo como pontos de fundamentais para interpretação da realidade e, a partir disto, produção de conhecimentos.

O subjetivismo, que Schütz e Luckmann (1973) chamaram de atitude natural, provém do entendimento de que a realidade tem origem na realidade experimentada a partir da vida quotidiana de cada indivíduo. É realidade composta pela consubstanciação de entendimentos de senso comum e de experiências vividas. No subjetivismo, as atividades são caracterizadas por motivos pragmáticos a partir dos quais os indivíduos agem em relação ao mundo. Logo, por definição, a atitude natural é não-reflexiva.

A perspectiva subjetiva tem como extremo o solipsismo, cujo pressuposto básico reside no entendimento de que a única realidade no mundo é o eu. É a "atitude que consiste em sustentar que o eu individual de que se tem consciência, com as suas modificações subjetivas, é que forma toda a realidade" (LINHARES, 1953, p. 463). No processo de produção de conhecimento, o subjetivismo tem importância por explicar o ato da reflexão, ou a atitude teórica. Os indivíduos estão aptos ou são levados a adotar uma atitude teórica quando são confrontados com uma série de circunstâncias novas, ou quando desejam superar dado obstáculo. A atitude teórica, por definição, é, assim, caracterizada pela sua ruptura com o fluxo de experiências, que constituem o mundo natural e condicionam comportamentos.

Como contraponto à perspectiva subjetivista, há o objetivismo cuja atenção é centrada na defesa de que, na construção do conhecimento, deve haver atribuição de relevância ou exclusividade à observação dos aspectos objetivos e mensuráveis de propriedades da realidade sob observação, pois considera que a apreensão do verdadeiro conhecimento tem origem em processo destinado a captar, de modo preciso, os objetos externos; logo, de maneira não desfigurada pela subjetividade cognoscente. Sob o olhar objetivista, a realidade existe e é externa ao congonscente; logo, independente de suas idiossincrasias, e é passível de ser metodologicamente apreendida, compreendida e reproduzida com precisão.

Ao ser aceito o ideal objetivista nos estudos organizacionais, é lícito argumentar que a função principal dos acadêmicos seria apreender a realidade e, a partir dela, emitir teorias sobre regularidades observadas. Por outro lado, não se pode negar que nesse processo eles não se isentam de efetuar diferentes escolhas idiossincráticas, por exemplo, quanto ao fenômeno, à abordagem e aos meios utilizados para apreender, compreender e interpretar a realidade. Deste modo, os teóricos, claramente, como qualquer outra pessoa, devem introduzir alguma proporção do seu dia-dia como atitude natural, caso almejem êxito em seus escritórios ou laboratórios. Da mesma forma, apesar dos atribulados problemas cotidianos dos praticantes gerenciais, sempre existirão e serão necessárias oportunidades para que dediquem algum tempo para adotar atitudes teóricas e refletir sobre as circunstancias que condicionam suas práticas. 
Entretanto, considerando a produção de conhecimentos, as evidências indicam que os pesquisadores em ciências administrativas passam mais tempo refletindo que os seus colegas praticantes. A diferença entre ambos pode residir no fato de os objetos de reflexão dos teóricos serem provenientes das atividades que se constituem em atitude natural dos primeiros. Por estas razões, seria errôneo atribuir, separadamente, qualquer dos dois tipos de conhecimentos a praticantes e a acadêmicos. Ao invés disto, há que se procurar entender melhor cada um deles e as conexões pelas quais todos são relacionados.

Tendo em conta, finalmente, as características dos estudos organizacionais, os esforços, tanto dos práticos quanto dos teóricos para interpretação da realidade e, a partir dela, geração de conhecimentos, o grau de subsunção aos ideais de subjetivismo ou de objetivismo somente pode ser definido em função da proporção relativa de tempo que cada um deles se insere em cada um desses modelos. Logo, soaria artificial tentar compreendê-los exclusivamente sob qualquer das duas perspectivas.

\section{Interações entre Teoria e Prática na Produção do Conhecimento}

Neste ponto, antes de abordar diretamente diferentes concepções sobre a produção de conhecimentos, é importante ressaltar que a epistemologia pode trazer contribuições importantes para explicitar importantes marcos para balizar o pensamento, tanto de praticantes quanto de teóricos. Em termos conceituais, "a epistemologia é conhecida como a teoria do conhecimento" (MOSER, 2002). Também pode ser concebida como uma teoria ou ciência do método ou das razões do conhecimento. Sua preocupação está em como os seres humanos obtém conhecimentos do mundo que os circunda, de como conhecem o que conhecem. A epistemologia, assim, fornece uma base filosófica a fim de estabelecer que tipos de conhecimentos são possíveis (o que pode ser conhecido) e critérios para decidir como o conhecimento pode ser julgado como adequado ou legítimo (BLAIKIE, 2007, p. 18). Nesta perspectiva, o mundo social pode ser submetido essencialmente a três modos, não mutuamente exclusivos, de conhecimento teórico em evolução, cada um com conjuntos de teses antropológicas implícitas, mas todos relacionados ao conhecimento prático, quais sejam: o conhecimento fenomenológico, o objetivista e o praxeológico (BOURDIEU, 1977, p. 3).

O conhecimento fenomenológico explicita verdades primárias do mundo social, como ocorre no mundo natural, considerando-as como auto-evidentes por definição; portanto, nega a possibilidade da autoreflexividade das práticas dos sujeitos (BOURDIEU, 1977, p. 53). Sob a perspectiva fenomenológica, a atenção dos estudos tende a ser voltada para aquilo que é considerado como certo (taken for granted) na atitude natural. A partir de uma "certeza" apriorística quanto a determinadas características do objeto sob análise, o modelo fenomenológico contribui, por exemplo, para penetrar em dada estrutura social e revelar a sua natureza socialmente construída, como defendem Berger e Luckmann (1966). Na área dos estudos organizacionais, uma ilustração desta abordagem pode ser verificada no artigo de Gephart (1978), sobre a degradação dos estatutos. Neste trabalho, o autor utiliza a abordagem etnometodológica para tornar explícita a natureza socialmente negociada das organizações.

Nessa linha, é natural que, no presente, um fenômeno possa ser considerado como certeza, mas poderá não sê-lo no futuro, assim como não o foi de modo constante no passado. Diante de tais condições, há que se lançar mão de outras alternativas epistemológicas para transcender a natureza puramente descritiva do conhecimento gerado a partir do modelo fenomenológico (BOURDIEU, 1990). Entretanto, a busca de novas possibilidades de geração de conhecimento, de modo algum, descarta a validade dos argumentos fenomenológicos; pelo contrário, há que se reconhecer que têm se mostrado bastante férteis para o aprofundamento da compreensão da natureza estruturada das relações sociais, tanto intra quanto extraorganizacionais.

O conhecimento objetivista constrói relações por meio da estruturação de práticas e representações. Com a estruturação há rompimento com o conhecimento primário (prático e tácito) por tomá-lo como autoevidente. O conhecimento, sob estas condições, se limita à apreensão da verdade objetiva da experiência primária e das estruturas do mundo social, desconsiderando, assim, as condições específicas sob as quais experiências primárias do mundo da vida são possíveis (BOURDIEU, 1977, p. 53). Portanto, sob tais condições, não lhe é natural aceitar a atitude teórica.

Ao categorizar o conhecimento dos sujeitos cujas ações produzem regularidades concretas, o modelo objetivista procura revelar estruturas de que dependem as atividades destes sujeitos, embora em relação às quais estejam normalmente desprevenidos. A teoria da contingência, por exemplo, mostra as relações 
entre construções organizacionais - tais como dimensão e tecnologia - que não são incorporadas conscientemente pelos atores, mas que influenciam seus modos de agir. Do mesmo modo, os estudiosos das práticas gerenciais - ao menos aqueles que abraçaram a revolução cognitiva - procuram revelar as estruturas cognitivas hierarquicamente agrupadas que poderiam explicar o comportamento dos atores organizacionais apesar de sua falha em considerar ou reconhecê-los de forma explicita (ILGEN; KLEIN, 1989; POWELL; DIMAGGIO, 1991).

Há, assim, riscos no modelo objetivista, haja vista que as regularidades concretas de que depende podem ser construídas de modo desvinculado do contexto histórico em que se desenvolve a ação, como se elas fossem anteriores à própria ação humana. A passagem da regularidade - daquilo que se repete com uma freqüência estatisticamente mensurável e a partir da fórmula pela qual ela é descrita - para um conjunto de regras conscientemente estabelecidas e respeitadas, ou a partir de uma regulamentação inconsciente por meio de um misterioso mecanismo social ou cerebral, são as duas maneiras mais usuais de se projetar do modelo da realidade para a realidade do modelo (BOURDIEU, 1990).

Nesse processo, as regularidades observadas são geralmente transformadas em regras e estruturas de comportamento. Nesta transformação, os desvios ocorridos passam a merecer mais atenção e explicações do que a origem das regularidades que tornam as regras plausíveis. Neste ponto, justamente, é que, geralmente, tem origem a confusão entre as coisas da lógica e a lógica das coisas. Não obstante essas limitações, o modelo objetivista de construção do conhecimento se constitui em momento necessário e desejável no desenvolvimento de uma teoria das organizações (BOURDIEU, 1977, 1973), uma vez que, tanto intra quanto inter organizacionalmente, existem diferentes estruturas relacionais que se identificam com o modelo em questão e cujos graus de regularidade podem ser determinados.

A fim de superar as limitações objetivistas do realismo da estrutura, que define um sistema de relações objetivas convertendo-as em generalidades previamente estabelecidas fora do contexto histórico do individuo ou do grupo, há que se passar do modelo opus operatum para o modelo modus operandis. O foco de atenção tem de deixar de ser direcionado para as estruturas estatísticas ou algébricas de regularidades e se concentrar nos princípios da produção desta ordem analisada. Com isso, abrem-se importantes espaços para a construção da teoria da prática, ou, mais precisamente, a teoria do modelo de produção de conhecimentos a partir das práticas (BOURDIEU, 1977).

O terceiro modelo de conhecimento teórico, o praxeológico, procura explicar como as regularidades são construídas e não o que deixa de enquadrar-se a elas. Ele reconhece tanto a natureza ampla e dinâmica do comportamento humano quanto as divergências, as inovações e as variações como propensões naturais dos ambientes organizacionais. A implicação sutil, ainda que extremamente significativa, é que, como estudiosos, devemos procurar um mecanismo para explicar como as regularidades deveriam ser cumpridas (GARFINKEL, 1967; POWELL; DIMAGGIO, 1991) e não procurar variáveis adicionais para explicar por que alguns exemplos divergem das "regras" organizacionais ou de comportamento.

A partir do conhecimento praxeológico, Pierre Bourdieu defende uma teoria de práticas, em que o modo prático de obtenção de conhecimentos inerentes a toda a prática se imponha como condição prévia para desenvolvimento de uma rigorosa ciência de práticas, com intenção de reverter a problemática construída pelo objetivismo, cuja finalidade é centrada na construção de um mundo social como um sistema de relações objetivas, independentes da consciência e das intenções individuais (BOURDIEU; 1977, p.3-10)

Avançar na direção de uma teoria de práticas requer a identificação de princípios generativos situados no interior do movimento de geração das próprias práticas. Com isso, seria possível o desenvolvimento de uma ciência das relações dialéticas das estruturas objetivas por meio das quais a perspectiva objetivista do conhecimento daria acesso às disposições estruturadas dos agentes. A agregação das disposições estruturadas dos agentes levaria à atualização das estruturas objetivas, que, por sua vez, influenciariam as primeiras. Ciclo que tenderia a reproduzir-se dialeticamente (BOURDIEU, 1973). O objetivo da análise da prática apreendida do mundo vivido não teria como propósito ampliar a subjetividade, mas explorar os limites da investigação objetiva (BOURDIEU, 1977, p. 7).

O conhecimento praxeológico defendido por Bourdieu, por não se preocupar somente com o sistema de relações captadas objetivamente, pode contemplar também as relações dialéticas entre estruturas objetivas e as disposições estruturadas, produzidas e tendentes a serem reproduzidas. Há geração de um processo dual de internalização da exterioridade e de externalidade da internalidade. Pressupõe, pois, uma ruptura com a produção objetivista de conhecimento, sem, contudo, desconsiderá-la. Há, na verdade, sua conservação e transcendência na medida em que existe incorporação daquele conhecimento, descartado 
de início, que flui das práticas (BOURDIEU, 1977, p. 3). Eis um ponto importante para aproximação de interesses tanto de teóricos quanto de praticantes, que atuam com inteção de compreender e influenciar, sob diferentes perspectivas, os contextos organizacionais.

\section{Conectando o Conhecimento Teórico ao Prático}

Se vistas como "atitudes" alternativas (SCHÜTZ; LUCKMANN, 1973) ou como diferentes formas de conhecimento (BOURDIEU, 1977), a teoria e a prática deixam de ser dividas como dimensões distintas que obstam aproximações entre acadêmicos e praticantes e vice versa. Todos, pois, tanto acadêmicos quanto praticantes, atingem seus objetivos desejados mediante uma dialética objetivista capaz de contemplar conhecimentos subjetivistas. Há, entretanto, tendências, tanto de acadêmicos quanto de práticos, de que, na medida em que seus objetivos estejam sendo atingidos dentro da atitude natural, apresentem propensão de atuarem fora de tal dialética (LORD; FOTI, 1986).

Contudo, ante obstáculos, circunstâncias imprevistas ou de novas experiências, tanto teóricos quanto práticos tendem a adotar estratégias de interpretação da realidade correspondentes aos três tipos de conhecimentos teóricos descritos. Primeiro, diante da pergunta "como é que se faz isto?", há busca de uma compreensão fenomenológica dos atos. Por outro lado, diante de várias possibilidades, poderiam perguntar-se "como é que as coisas são geralmente feitas?" ou "como é que as coisas deveriam ser feitas nesta situação?". Nesta situação há perfeita subsunção ao modelo objetivista, por sua ênfase no conhecimento de regularidades observadas. Entretanto, se a pergunta for "o que nos levou a fazer as coisas desta maneira?" ou "como poderemos começar a fazer as coisas de outra maneira?" há que se lançar mão do conhecimento praxeológico.

Como visto, com o modelo objetivista há tendências de aplicar regularidades sem devidamente considerar os comportamentos dos indivíduos, o modelo fenomenológíco é mais aplicável àquelas regularidades de que dependem nossos comportamentos, enquanto o modelo praxeológico àquelas regularidades que tem origem no nosso comportamento, sem revelar, porém, como estas regularidades vieram a se constituir, ou como elas poderiam ser incorporadas em atividades futuras.

Os conhecimentos objetivistas e fenomelógicos que surgem da atitude teórica não podem condicionar, mas tão-somente afetar nosso comportamento dentro da atitude natural. São oriundos, pois, de nossas repetidas exposições às estruturas do mundo socialmente construído que culminam por desenvolver roteiros e esquemas interpretativos que constituem as nossas rotineiras formas de comportamentos (ASHFORTH; FRIED, 1988; LORD; FOTI, 1986; POWELL; DIMAGGIO, 1991).

Diante das regularidades de comportamento, são justificáveis as construções de estruturas físicas ou simbólicas para expor rotinas com maior facilidade. Assim, mediante reconhecimento da possibilidade de outras regularidades por meio de conhecimentos teóricos, os indivíduos tornam-se capazes de idealizar novos esquemas interpretativos que possam resultar em novas formas de comportamento. Em função da tendência de perpetuação de mudanças nas rotinas, as estruturas físicas, simbólicas e organizacionais, por conseguinte, também tendem a mudar continuamente. Atuar nessa dinâmica, que contempla a constante construção e reconstrução do modo de captar e interpretar a realidade, demanda a utilização de uma dialética pela qual, de um lado, as estruturas externas sejam internalizadas como geradoras de estruturas para o comportamento e, do outro, as estruturas internas sejam externalizadas na forma de comportamentos que nos permitam identificá-las e conhecê-las como estruturas objetivas (BOURDIEU, 1977). Deste modo, o modelo praxeológico procura tornar explícita esta dialética entre conhecimento teórico e prático. Apesar de seu grande potencial para contribuir para compreensão das organizações, são ainda poucos os estudos sobre o modelo praxeológico. Alguns estudos vinculados à teoria institucional demonstram afinidades com o modelo praxeológico (POWELL; DIMAGGIO, 1991), embora, caracteristicamente, os esforços empíricos para desenvolvimento do modelo tenham enfatizado a incorporação de elementos externos mais do que a externalidade de elementos internos.

O domínio teórico dos esquemas interpretativos pode também ser considerado como tentativa de compreender teoricamente o mecanismo pelo qual esta dialética pode ocorrer. Entretanto, a importância do modelo praxeológico se revela mais nítida em estudos empíricos. Neste sentido, os estudos de Barley (1986, 1990), sobre a introdução de novas tecnologias, fornecem uma excelente indicação sobre a importância das percepções neste tipo de pesquisa. Na falta de maiores ilustrações, a questão que se coloca diz respeito ao motivo pelo qual são relativamente poucos os realizados a partir deste modelo 


\section{Dicotomias no Tratamento Acadêmico da Realidade Organizacional}

O argumento que tentamos defender é que, se o abismo entre a teoria e a prática tem de ser preenchido, ou eliminado, e mais consistentes teorias das organizações desenvolvidas, será necessário que acadêmicos que estudam organizações deixem de lado dicotomias como "micro" e "macro", e teorias e práticas administrativas. O “momento" praxeológico ocorre, pois, precisamente no ponto em há junção entre teorias e práticas; logo, a demarcação dos estudos organizacionais com fundamentos nestas duas dimensões inibe possibilidades de construção praxeológica.

Tendo em conta que a divisão entre estruturas cognitivas e sociais as desvincula das suas origens (BOURDIEU, 1977), enfocar somente as esferas macro ou micro atribui, de modo artificial, às estruturas um grau de realismo que provavelmente não teriam de outro modo. Naturalmente, como reflexo desta estratégia epistemológica, os praticantes são levados a ver as estruturas cognitivas desvinculadas das estruturas sociais a partir das quais emergiram. Do lado dos não-praticantes, surgem tendências de presumirem que as estruturas das organizações podem ser estudadas independentemente dos sujeitos a partir de cujos comportamentos são constituídas. Talvez a complexidade envolvida para articular concomitantemente essas dimensões tenha se tornado empreendimento desencorajador para muitos pesquisadores na perseguição do conhecimento praxeológico.

Existem, porém, no domínio das ciências sociais, em geral, e dos estudos organizacionais, em particular, correntes de pensamento que procuram desenvolver conhecimentos praxiológicos cujos impactos estão ainda por ser sentidos nas teorias administrativas. Caso persistam em elevação as suas influências, a distinção entre teoria e prática nos estudos de administração terá reduzido o espaço para sustentação de diferenciação entre essa duas dimensões interconectadas e mutuamente dependentes.

Sob essa perspectiva, fazendo uma analogia com a divisão entre estudos em psicologia e em sociologia organizacional, em assonância com o que relatam Nord e Fox (1999, p. 190), percebemos que a linha divisória começa a se tornar tênue. Na psicologia, por exemplo, estudos pioneiros estão discutindo as ações dos indivíduos de forma suspeitosamente sociológica, isto é, nas fronteiras entre as duas ciências. Da mesma forma, estudiosos cujas afinidades são mais sociológicas (BOURDIEU, 1990) tendem a perder espaço quando suas teorias reduzem o potencial de explicação de impactos das ações individuais.

Diante dos reflexos de posicionamentos extremados, no continuum entre teoria e prática, estudiosos passam crescentemente a defender a desnecessidade e a dificuldade de sustentar as tradicionais distinções entre os dois campos que tenderam, e ainda tendem em boa parte da literatura, a ser distintos (CHIA; MACKAY, 2007; HODGKINSON; CLARKE, 2007; THOMPSON, 1991).

A naturalização e desenvolvimento de estudos interdisciplinares têm se constituído em significativas contribuições para aproximação das dimensões práticas e teóricas. O surgimento de atividades interdisciplinares se deve, em grande parte, ao estruturalismo dos anos de 1960 (BOURDIEU, 1990). Na atividade estruturalista o indivíduo toma o real e o decompõe e o recompõe. Entretanto, não reproduz o real; apenas simula-o. Deste modo, é fortalecida a técnica e a tecnicidade, haja vista que a técnica seria a essência de toda a criação. Nesta criação, a atividade estruturalista se liga a uma técnica que comporta duas operações fundamentais: corte (em unidades discretas, em átomos de significação) e arranjo (LEFEBVRE, 1967, p. 84). Exemplo deste processo, em termos metodológicos, pode ser verificado no trabalho de Procopiuck e Frey (2009, p. 691-692).

Neste arranjo, ganha especial relevância o relacionamento entre as partes que constituirão o todo. Esta constituição implica em totalidade e interdependência e, assim, na exclusão de todos os elementos relacionados à estrutura por mera justaposição. Nesta seleção de elementos que representarão a realidade estruturada somente interessam aqueles conjuntos com características que expressam que o todo é maior que a simples soma das partes. A construção do conhecimento nesta perspectiva estruturalista consiste em “um perpétuo ir e vir das partes ao conjunto e do conjunto às partes" (VIET, 1967, p. 8).

Nesse processo "é a natureza dos fatos que estudamos que nos incita a distinguir, nêles, o que pertence à estrutura, o que pertence ao evento" (LÈVI-STRAUSS, 1970, p. 61). A principal novidade do estruturalismo é que tudo está interligado e isso nos ajudou a compreender que cada elemento de um sistema é caracterizado pela sua relação com todos os outros elementos e que a significação nasce desta interrelação (BOURDIEU, 1990).

Esta linha de pensamento foi difundida e a partir da qual surgiram diversas correntes conhecidas como 
"pós-modernismo" e "pós-estruturalismo". De todas as questões relacionadas com estes movimentos, as conseqüências da chamada "virada lingüística" são as que se mostraram mais aptas para afetar os estudos organizacionais. Elas já são percebidas no âmbito dos estudos organizacionais, a exemplo do artigo de Linstead e Grafton-Small (1992) sobre cultura organizacional, que fornece vários exemplos de como as literaturas pós-modernistas e pós-estruturalistas podem contribuir para os estudos organizacionais.

Na seção a seguir, gostaríamos de mostrar como estas abordagens minam as concepções tradicionais sobre estruturas organizacionais e indicar os diferentes efeitos que podem ter sobre o comportamento organizacional e nas perspectivas epistemológicas.

\section{As Organizações Subjetivas}

As entidades do mundo como o percebemos não são exaustivas em relação ao modo como devemos conhecê-las. Ao contrário de objetos geométricos, estas entidades não são formalmente ligadas e compostas de acordo com regras axiomáticas de construção. Ao invés disto, são abertas a uma infinita variedade de perspectivas a partir das quais os "objetos" do mundo são criados (MERLEAU-PONTY, 1964). Este é o caso, e.g., dos padrões e regulamentos observados nas atividades sociais, e dos padrões e regularidades observadas nas organizações sociais.

As estruturas decorrentes da sistematização ou organização do universo em fatos e em objetos de natureza implícita ou explicita devem ser compreendidas por meio de um ato instrumental a elas inerente (POWELL; DIMAGGIO, 1991) que reflita as perspectivas, as percepções e as intenções dos indivíduos em interações reais (FOUCAULT, 1965, 1978). Isso se torna necessário e indispensável em face de as organizações não poderem ser dissociadas do mudo real (RORTY, 1989, p. 5). Na busca de apreensão e compreensão da realidade, se os pesquisadores estão preparados para discernir uma variedade maior de objetos e de estruturas quando comparados aos praticantes, não necessariamente é indicativo de que ocupem posição epistemológica privilegiada. A posição dos praticantes, neste caso, pode refletir opções que culminaram na desistência de outras perspectivas divergentes da realidade organizacional.

Portanto, ontologicamente, as estruturas não devem ser compreendidas como reais e imutáveis, inerentes às ações e relações sociais. Elas representam regularidades que se tornaram reais em suas aparências e conseqüências. Devido ao efeito de estruturação que exercem sobre outras atividades elas são sustentadas numa coerência que torna suas realidades difíceis de refutar. Evidência disso ocorre quando equipamentos, ferramentas ou maquinaria são especificamente desenvolvidos e implementados para transformar o exercício destas regularidades numa rotina.

As estruturas, portanto, podem ser consideradas tanto como suporte como obstáculo (STURROCK, 1986). Em virtude de as estruturas representarem relações e atividades rotineiras, são, de fato, predisposições para o exercício de atividades práticas e, em relação a estas, se revelam como bases de suporte. Entretanto, a partir do momento em que estas atividades se constituem em barreiras para implementação de outras, podem igualmente ser vistas como estímulos às pré-existentes. Deste modo, para as organizações, num contexto mais amplo, as estruturas ambientais existentes podem encorajar algumas configurações organizacionais enquanto outras são totalmente desencorajadoras.

Numa visão estruturalista dialética, a organização é vista como uma unidade social complexa sob e em relação à qual interagem diferentes grupos sociais. Dentre suas premissas, assume-se a existência de conflitos no desenvolvimento das organizações, embora haja compartilhamento de interesses por tais grupos. Nessas bases, buscam-se meios de interpretar e, a partir disso, desenvolver maneiras de tratá-los. Há, na verdade, reconhecimento de dilemas da organização entre as necessidades organizacionais e as necessidades de seu pessoal, entre racionalidade e irracionalidade, entre disciplina e autonomia, e entre posições e divisões (ETZIONI, 1989, p. 68).

As estruturas por possuírem grande predisposição de se reproduzirem e por tenderem a fazê-lo sempre com quase perfeição, são consideradas reais e imutáveis. Entretanto, como estruturas resultantes de construção social, as suas reproduções não podem acontecer sem a cooperação do agente social que, de fato, as trouxe à vida e que exerce a atividade social sujeita aos efeitos da estruturação.

Além do mais, a manifestação das estruturas nas ferramentas desenvolvidas para servirem de apoio à realização de ações desejadas desenvolve um habitat que, por sua vez, pode se tornar um obstáculo para a realização de atividades de modo diferente ao previsto pela estrutura física já implementada (ILLICH, 
1973). Entretanto, é importante ressaltar que, as estruturas de comunicação e de atividades, e o habitat que age para estruturar estas atividades, não "existiriam" se o agente social deixasse de adotar o comportamento esperado. Por esta razão, não se pode estudar as práticas sem questionar como tal agente que ocupa aquele ponto nodal se torna predisposto a realizar uma prática necessária para o funcionamento harmonioso da organização. Neste sentido, as estruturas organizacionais não podem ser entendidas sem a concomitante compreensão dos indivíduos cujos comportamentos individuais e coletivos estão sendo estruturados.

\section{Em Direção a uma Teoria da Prática?}

A partir da discussão sobre estruturas organizacionais empreendida até este ponto, é possível antever que uma teoria organizacional deva levar em consideração o papel interessado e constitutivo dos comportamentos dos indivíduos no desenvolvimento de estruturas organizacionais. É também permitido afirmar que, frente às constantes mudanças de comportamentos individuais, uma teoria das organizações deva também levar em consideração o papel constitutivo das organizações no desenvolvimento de tais subjetividades, embora seja este papel apenas parcial. Essas relações, se expressas por meio de diagrama, se apresentam circularmente: as organizações constituem subjetividades que, por sua vez, constituem organizações. Como sistema aparentemente fechado, não permite esclarecer como as mudanças podem ocorrer, especialmente da forma como as descrevemos.

O sistema, contudo, somente é fechado se abordado de forma sincronizada. Esta, apesar de suas significativas limitações, tende a ser a estrutura dominante do modelo subjetivista de estudo. Dentro deste modelo, portanto, é difícil esperar o desenvolvimento teorias administrativas robustas, uma vez que, como é evidente, as organizações estão sujeitas a contínuas transformações. Não obstante, torna possível desenvolver, por exemplo, análises de uma grande quantidade de organizações que permitam explicitar diferentes visões sobre uma variedade de correlações organizacionais, tais como: tamanho, tecnologia, estrutura e desempenho.

Entretanto, não é possível negar que a estabilidade de tais correlações é fundamentalmente dependente dos indivíduos cujos comportamentos as constituem e as mantém. Assim, as organizações nascem a partir da ação e somente continuam a existir por meio do encadeamento de ações subseqüentes. Compreender a regularidade e estabilidade das ações, como ressalta Gergen (1982, p. 19), demanda que se considerem dois fundamentos universais para a atividade humana. A reflexiva, como primeira delas, trata da capacidade de o indivíduo aprender e se beneficiar de experiências passadas. Com isso, tenta não repetir erros e, com o uso das suas melhores habilidades, seguir caminhos ou conjuntos de ações que acredita o levarem a maiores probabilidades de sucesso. Nessa linha, no caso das organizações, para que obtenham sucesso, dependem de restrições ou de oportunidades que influenciem seu comportamento e tenham de ser idênticas àquelas de circunstâncias passadas. Diante da insuficiência da reflexividade como argumento, como segunda atividade humana, a capacidade de reconceptualização permite que os indivíduos reavaliem suas experiências passadas e alterem seus significados em função de novas realidades que se descortinam e com novos conhecimentos apreendidos com transcorrer do tempo.

Com base na interação entre a capacidade de reflexividade e de reconceptualização, os indivíduos podem contribuir significativamente no processo de desenvolvimento e adaptação das organizações a novas e diferenciadas circunstâncias. Os indivíduos, com isso, possuem elevada capacidade de estabelecer alternativas, revendo alguns conceitos e abandonando outros. Como conseqüência, não há necessidade de falha em dada ação para que sejam procuradas outras; há, pois, a possibilidade de decisão simplesmente por se tentar algo novo. Assim, tanto por meio da reflexividade quanto da imaginação, há motivos para se esperar que as estruturas ou práticas organizacionais tendam a certa estabilidade com o transcorrer do tempo.

Nessa linha, a plenitude e a coerência do sistema, quando visualizadas sincronicamente, desvanecem num processo dialético de contínua negociação e de reprodução imperfeita, que oferece as condições para que mudanças facilmente sejam concebidas. Para aqueles sujeitos às suas influências, as estruturas que caracterizam um determinado ambiente organizacional - tanto físico quanto social - produzem nos indivíduos um repertório de padrões e esquemas interpretativos (GIOIA; POOLE, 1984; LORD; FOTI, 1986). Há, pois, emergência de um habitus, que funciona como estrutura geradora para as práticas administrativas, e tende a produzir comportamentos que, nas suas regularidades, parecem mais objetivos e regulamentados, apesar de não serem produto de simples cálculos racionais ou reflexos mecânicos 
(BOURDIEU, 1973, 1977, 1990).

O conceito de habitus, como elemento condicionante e condicionador de ações do agente num campo social, contempla as noções de ethos, valores calcados em princípios de ordem, não-conscientes, que regem a moral cotidiana; de hexis, princípios interiorizados pelo corpo, como posturas, expressões e aptidões corporais adquiridas, não-naturais; e de eidos, princípio de construção da realidade com sustentação em uma crença pré-reflexiva no valor indiscutível de instrumentos de construção e de objetos construídos, i.e, um modo intelectual específico de apreender e pensar a realidade (THIRY-CHERQUES, 2006, p. 34).

Infra-consciente e parcialmente autônomo, o habitus se constitui numa espécie de segunda natureza, que situado historicamente, vincula o agente a dado meio social, permitindo-lhe o desencadeamento de ações sem cálculo ou controle conscientes, sem, pois, que haja uma pré-definição dos fins. Contém em si o conhecimento e reconhecimento das regras do jogo, cuja aquisição ocorre mediante aprendizagem explícita ou implícita. Opera como um sistema de esquemas geradores de estratégias que podem ser objetivamente conformadas aos interesses dos seus autores, sem, entretanto, terem sido concebidas com tal fim (THIRY-CHERQUES, 2006, p. 34). Estas são as estruturas da atitude natural (SCHÜTZ; LUCKMANN, 1973) que governam a maior parte de nossas atividades diárias no contexto da organização.

o habitus organizacional é um conjunto de dispositivos que leva um agente a agir de modo determinado sem ser condicionado pelo senso mecânico de comportamentos associados a regras. O estabelecimento destes dispositivos acontece por meio de um processo gradual de inculpações em que experiências passadas tendem a ter influências maiores do que experiências recentes. Adquiridos ao longo do tempo e em um nível pré-consciente, os dispositivos do habitus, em si, são considerados estruturados. Em sua capacidade geradora, portanto, eles se tornam estruturas em formação na medida em que produzem comportamentos estruturados de forma inconsciente e que são adaptados de forma pré-consciente a uma variedade de situações contextuais nos quais são desenvolvidos (THOMPSON, 1991). Por intermédio do habitus, as estruturas organizacionais, que precedem nosso ingresso no mundo das organizações, são internalizadas via experiências organizacionais anteriores e agem no sentido de reproduzir estas estruturas de forma contínua, se não obstacularizadas por atitudes teóricas.

Embora as estruturas do habitus sejam, em muitos casos, transferíveis e adaptáveis às variações com lastro em circunstâncias anteriores, emergirão situações em que as rotinas e os esquemas já estabelecidos não serão adequados e, portanto, haverá necessidade de se adotar uma atitude teórica em busca de alternativas mais ajustadas (SCHÜTZ; LUCKMANN, 1973). Alternativamente, condições de adaptação podem também ser auto-induzidas por meio de planejamentos estratégicos ou de pura reflexão. Neste momento é que o modelo teórico de conhecimento se torna relevante no mundo das práticas. Na condição de pesquisador, o indivíduo, pois, deverá gerar alternativas levando em consideração aquilo que geralmente não é questionado. As estruturas organizacionais físicas e simbólicas, desde as mais simples até as mais complexas, devem, assim, ser constantemente dissecadas a fim de que se possa determinar se estão adequadas para fazer frente às oportunidades ou restrições presentes ou, do contrário, se devem ser reconstituídas sob outros modelos ou condicionantes.

Da mesma forma, um conjunto de observações deve ser examinado, de uma perspectiva objetivista, para determinar se não são apenas padrões e regulamentos que indicam uma melhor maneira de organizar ou de realizar as atividades organizacionais. Se for o caso, é provável então que esta maneira particular seja experimentada e, se for bem sucedida, é natural que ela seja experimentada mais e mais vezes. Esta forma de fazer as coisas, eventualmente poderá se tornar parte do habitus e tenderá a ser incorporada nas atividades da atitude natural, apesar de sua origem ser de ordem teórica.

Análises objetivistas e fenomenológicas são ainda necessárias, pois, em vários casos, elas representam a origem da reflexão sobre arranjos atuais e sobre futuras possíveis alternativas. Uma teoria em ciências administrativas, contudo, deve ser fraseológica a fim de levar em consideração a forma como insights reflexivos são incorporados na atitude natural, que, em si, é constitutiva das estruturas organizacionais atuais. O objetivo, portanto, é fornecer meios que possam levar essas condições em consideração. Nessa direção, a discussão sobre linguagem e pós-estruturalismo pode ser uma possibilidade. Se a linguagem se constituir em elemento tão fundamental quanto se acredita ser a virada lingüística, seria plausível que os sustentáculos do habitus estariam na própria natureza da lingüística, ou, pelo menos, seria linguisticamente construído. Contudo, conclusões definitivas, ainda inexistem; logo, continuam a demandar novas reflexões teóricas e estudos empíricos. 
O desafio para uma teoria da Administração, portanto, é estudar o processo pelo qual as organizações desenvolvem ao longo do tempo a reflexividade e a imaginação dos atores organizacionais. Nessa direção, análises objetivistas e fenomenológicas são ainda necessárias, pois, em vários casos, elas representam a origem da reflexão sobre arranjos atuais e sobre futuras possíveis alternativas.

\section{Considerações Finais e Sugestões}

Diante das análises empreendidas no presente trabalho, não seria impróprio afirmar que grande parte dos pesquisadores em ciências da Administração mais se parecem com historiadores do que com cientistas que desenvolvem suas atividades no âmbito das ciências naturais. De um lado, os pesquisadores que se consideram teóricos, levam em consideração a história de como a teoria é despejada nas estruturas organizacionais visíveis e como se manifesta nas interações e nas relações dos atores organizacionais. De outro lado, os que se posicionam como praticantes de técnicas gerenciais também levam em consideração a história, porém da forma como ela contribui para a constituição da objetividade. As organizações, se vistas sob esta perspectiva, são resultados da harmonia das formas históricas, como habitat e habitus (BOURDIEU, 1981). Neste sentido, nem o habitat nem o habitus podem, separadamente, ser considerados como uma organização; ao invés disto, é a junção dos dois que produz e reproduz as organizações (THOMPSON, 1991).

Entretanto, "quando a mesma história é vivida tanto no habitat quanto no habitus, tanto nas disposições quanto nas posições, neste caso, a história se comunica e se reflete em sua própria imagem" (BOURDIEU, 1981, p. 306). Com esta experiência, a organização se torna natural; ela aparentemente se apresenta como pré-definida e pré-estruturada, não como fruto de nossa criação, mas como algo em que temos de viver. Entender as estruturas organizacionais como pré-existentes é reafirmá-las como são e ignorar o desenvolvimento dialético do habitus e do habitat.

Assim, em complemento à literatura objetivista, que identifica as estruturas de cada campo, é necessário um estudo praxeológico que leve em consideração o compromisso ontológico por meio do qual "um corpo, adequado à história, amolda imediata e absolutamente as coisas que vivem a mesma história" (BOURDIEU, 1981, p. 306). É importante frisar, como já foi discutido antes, que a divisão das ciências administrativas em campos "micro" e "macro" se opõe a esta forma de estudo. O posicionamento do discurso teórico em qualquer destes campos leva os estudiosos a buscarem coerência e desenvolvimento das estruturas tão-somente no âmbito interno de seus próprios campos de estudos.

Em grande parte, apesar do reconhecimento de que o campo da prática organizacional está necessitando de uma agenda para o futuro, parece existirem poucos estudiosos com disposição mudar as estruturas que a sustentam sua forma atual (WEICK, 1992). Quanto a este problema, Pierre Bourdieu explica que, talvez, a dificuldade resida no fato de que "a análise das estruturas objetivas não pode ser separada da análise do desenvolvimento das estruturas mentais" (BOURDIEU apud HONNETH; KOCYBA; SCHWIBS, 1986, p. 43)

No campo dos estudos organizacionais, uma importante implicação dos pressupostos da teoria da prática é representada pela possibilidade de concepção da organização como estrutura social condicionante e condicionada pela produção e reprodução de ações estratégicas de agentes ou grupos de agentes nela implexos ou daqueles situados em contextos mais amplos da sociedade que sobre ela exercem influências. Como a própria estrutura é resultado das práticas dos agentes envolvidos em ações estratégicas originadas nesses contextos, com a teoria da prática há possibilidades de identificação de peculiaridades da organização que lhe atribuem identidade própria a partir de seus sistemas de produção e reprodução. Deixa-se, portanto, de utilizar abordagens analíticas que partam de modelos ou estruturas gerais pré-concebidas para identificar sistemas sociais com lastros na própria prática estratégica e, com base neles, aplicando o princípio da diferenciação, classificá-las em categorias que reflitam com maior propriedade e fidedignidade a dinâmica da realidade a elas subjacentes.

À guisa de conclusão, esperamos que a evolução dos estudos organizacionais tenda a deixar de ser condicionada pela clivagem entre teoria e prática. Do contrário, é bastante provável que muitos não consigam transitar livremente entre essas duas dimensões interconectadas e inter-relacionadas do conhecimento em função da existência de abismo intransponível entre elas. A ampliação de tal abismo certamente contribuirá para obstrução cada vez mais intensa para a produção de conhecimentos a partir dos estudos organizacionais. 


\section{Referências}

ASHFORTH, B. E. e FRIED, Y. The mindlessness of organizational behaviors. Human Relations, v. 41, n. 4, p. 305-329, 1988.

ASTLEY, W. G.; ZAMMUTO, R. F. Organization science, managers, and language games. Organization Science, v. 3, n. 4, p. 443-460, 1992.

AUDET, M. Le procès des connaissances de l'administration. In: AUDET, M.; MALOUIN, J. (Eds.). La production des connaissances scientifiques de l'administration. Quebec: Université Laval, 1986. p.23-56.

BARLEY, S. R. Technology as an occasion for structuring: evidence from observations of CT scanners and the social order of radiology departments. Administrative Science Quarterly, v. 31, n. 1, p. 78-108, 1986.

. The alignment of technology and structure through roles and networks. Administrative Science Quarterly, v. 35, n. 1, p. 61-103, 1990.

BERGER, P. L. e LUCKMANN, T. The social construction of reality: A treatise in the sociology of knowledge. Garden City: Doubleday, 1966.

BLAIKIE, N. Approaches to social inquiry: advancing knowledge. 2. ed. Cambridge: Blackwell Publishers, 2007.

BOURDIEU, P. The three forms of theoretical knowledge. Social Science Information, v. 12, n. 1, p. 53-80, 1973. . Outline of a theory of practice. Cambridge: Cambridge University Press, 1977.

Men and machines. In: KNORR-CETINA, K.; CICOUREL, A. V. (Eds.). Advances in social theory and methodology: toward and integration of micro-and macro sociologies. Boston: Routledge, 1981. p. 304-317. The logic of practice. Cambridge: Polity Press, 1990.

CHIA, R.; MACKAY, B. Post-processual challenges for the emerging strategy-as-practice perspective: Discovering strategy in the logic of practice. Human Relations, v. 60, n. 1, p. 217-242, 2007.

CLEGG, S. R.; HARDY, C. Introdução: organização e estudos organizacionais. In: CLEGG, S.; HARDY, C; NORD,. D. (Orgs.). Handbook de estudos organizacionais. São Paulo: Atlas, 1999. p. 27-57. 3v.

ETZIONI, A. Organizações modernas. 8. ed. São Paulo: Pioneira, 1989.

FOUCAULT, M. Madness and civilization: a history of insanity in the age of reason. New York: Vintage Books, 1965.

The history of sexuality: An introduction. New York: Vintage Books, 1978.

GARFINKEL, H. Studies in ethnomethodology. Englewood Cliffs: Prentice Hall, 1967.

GEPHART JR., R. P. Status degradation and organizational succession: an ethnomethodological approach. Administrative Science Quarterly, v. 23, n. 4, p. 553-581, 1978.

GERGEN, K. J. Toward transformation in social knowledge. New York: Springer-Verlag, 1982.

GIOIA, D. A.; POOLE, P. P. Scripts in organizational behavior. Academy of Management Review, v. 9, n. 3, p. 449-459, 1984.

HODGKINSON, G. P.; CLARKE, I. Exploring the cognitive significance of organizational strategizing: A dualprocess framework and research agenda. Human Relations, v. 60, n. 1, p. 243-255, 2007.

HONNETH, A.; KOCYBA, H.; SCHWIBS, B. The struggle for symbolic order: an Interview with Pierre Bourdieu. Theory, Culture and Society, v. 3, n. 3, p. 35-51, 1986.

ILGEN, D. R.; KLEIN, H. J. Organizational behavior. Annual Review of Psychology, v. 40, p. 327-351, 1989.

ILLICH, I. Tools for conviviality. New York: Harper \& Row, 1973.

KING, G.; KEOHANE, R. O.; VERBA, S. Designing social inquiry: scientific inference in qualitative research. Princeton: Princeton University Press, 1996.

LEFEBVRE, H. Reflexões sobre o estruturalismo e a história. In: ESCOBAR, C. H. (Ed.). O método estruturalista. Rio de Janeiro: Zahar, 1967.

LËVI-STRAUSS, C. Aula inaugural. In: LIMA, L. C. (Ed.). O estruturalismo de Lèvi-Strauss. 2. ed.. Petrópolis: Vozes, 1970. p.45-77.

LINHARES, T. Introdução ao mundo do romance. São Paulo: José Olympio, 1953. 
LINSTEAD, S.; GRAFTON-SMALL, R. On reading organizational culture. Organization Studies, v. 13, n. 3, p. 331-355, 1992.

LORD, R. G.; FOTI, R. J. Schema theories, information processing, and organizational behavior. In: SIMS, H. P.; GIOIA, D. A. (Eds.). The thinking organization. New York: Jossey-Bass, 1986. p.20-48.

MARSDEN, R.; TOWNLEY, B. Introdução: a coruja da Minerva: reflexões sobre a teoria na prática. In: CLEGG, S.; HARDY, C; NORD,. D. (Orgs.). Handbook de estudos organizacionais. São Paulo: Atlas, 1999. p.31-56. 3v.

MATTOS, P. L. C. L. de. Teoria administrativa e pragmática da linguagem: perspectivas para problemas que afligem as relações entre acadêmicos e consultores, educadores e educandos. Revista de Administração Contemporânea, v. 7, n. 2, p. 35-55, 2003.

MERLEAU-PONTY, M. The primacy of perception and other essays. New York: Northwestern University Press, 1964.

MOSER, P. K., (Ed). The Oxford handbook of epistemology. Oxford: Oxford University Press, 2002. p. 566.

NORD, W. R.; FOX, S. O indivíduo nos estudos organizacionais: o grande ato de desaparecimento? In: CLEGG, S.; HARDY, C; NORD,. D. (Orgs.). Handbook de estudos organizacionais. São Paulo: Atlas, 1999. p. 186-225. 3v.

OSTSMAN, O. Mudar o trabalho: as experiências, os métodos, as condições de experimentação social. Lisboa: Fundação Calouste Gulbenkian, 1978.

POWELL, W. W.; DiMAGGIO, P. J. The new institutionalism in organizational analysis. London: University of Chicago Press, 1991.

PROCOPIUCK, M.; FREY, K. Articulações organizacionais em redes de políticas públicas no ciberespaço: o caso da política de difusão social de TICS em Porto Alegre e Curitiba. Organizações \& Sociedade, v. 16, n. 51, p. $687-706,2009$.

REED, M. Teorização organizacional: um campo historicamente contestado. In: CLEGG, S.; HARDY, C; NORD,. D. (Orgs.). Handbook de estudos organizacionais. São Paulo: Atlas, 1999. p.61-98. 3v.

RORTY, R. Contingency, irony, and solidarity. Cambridge: Cambridge University Press, 1989.

SAUTU, R. et al. Manual de metodología: construcción del marco teórico, formulación de los objectivos y elección de la metodología. Buenos Aires: CLACSO, 2005.

SCHÜTZ, A.; LUCKMANN, T. The structures of the life-world. Evanston: Northwestern University Press, 1973. STURROCK, J. Structuralism. London: Paladin, 1986.

THIRY-CHERQUES, H. R. Pierre Bourdieu: a teoria na prática. Revista de Administração Púbica, v. 40, n. 1, p. 27-55, 2006.

THOMPSON, J. B. Editor's Introduction. In: BOURDIEU, P. (Ed.). Language and symbolic power. Cambridge: Polity Press, 1991. p.1-31.

TILLY, C.; GOODIN, R. E. It depends. In: GOODIN, R. E.; TILLY, C. (Eds.). The Oxford handbook of contextual political analysis. Oxford: Oxford University Press, 2006.

VIET, J. Métodos estruturalistas nas ciências sociais. Rio de Janeiro: Tempo Brasileiro, 1967.

WEICK, K. E. Agenda setting in organizational behavior: a theory-focused approach. Journal of Management Inquiry, v. 1, n. 3, p. 171-182, 1992. 